\title{
Effective Practices in the Electrical Systems Service Course
}

\author{
Edward Wheeler, Cliff Grigg, Zachariah Chambers, Richard A. Layton \\ Rose-Hulman Institute of Technology
}

\section{Introduction}

There is a national need to improve the electrical systems service courses taken by mechanical engineering (ME) students. The systems that engineers work with are becoming increasingly multidisciplinary. Engineers, particularly team leaders and engineering managers, are finding it increasingly important to acquire some technical competence outside their core disciplines. ${ }^{1}$ Product design and development is coming to be viewed not as an assortment of problems in mechanics, electronics, hydraulics, and so forth, but as a systems problem, requiring a systems perspective. The automobile industry is only one example of an industry where this trend can be readily identified. ${ }^{2}$ Thus, knowledge of electrical systems is an integral part of every mechanical engineer's background, and it follows that electrical systems service courses are an integral part of mechanical engineering curricula.

Those who teach these courses know that the problems are not primarily ones regarding content but rather of delivery. The very real problems that can appear in these service courses are often due to a lack of motivation or interest on the part of students, a classroom/laboratory design that does not meet the discipline-specific needs of the students, and a learning environment lacking tools that encourage students to come to class prepared and that permit them to study effectively outside of class. We focus on the role that the course plays in the ME curriculum and the benefits it offers in the ME students' education.

Motivating students and engaging their interest is vital to the success of any course. ${ }^{3}$ These courses, however, often fail to interest or motivate students and many times do not meet their primary objective of enabling students to use the principles of electrical systems in their chosen discipline. This is partly because material is offered to the mechanical engineering student from the perspective of an electrical engineer. From the students' viewpoint, these service courses become a collection of unrelated topics with little relevance to their interests. Mechanical engineering departments must work with electrical and computer engineering (ECE) departments to improve these courses and to help ensure that the needs of $\mathrm{ME}$ students are met. $\mathrm{ME}$ departments can take steps to ensure that students come to these classes motivated and engaged. They can help faculty from ECE choose relevant topics that interest ME students.

In this paper, we describe steps being taken at Rose-Hulman Institute of Technology to address these issues. This is an ongoing project and course design will likely undergo significant modifications over the next 2-4 years. We report here the steps taken to date and our present plans. We begin with some background information, follow with course and curriculum design considerations, and conclude with our plans for assessment. 


\section{Background}

Two of the authors (EW and CG), not being satisfied with the observed outcomes in this service course, surveyed faculty in the mechanical department with the object of obtaining suggestions for improvement. The conclusions drawn were that:

- traditional "survey" courses do not meet student needs,

- these courses should concentrate on topics which relate to professional practice in the students' discipline, and

- experiential reinforcement of classroom instruction is highly desirable.

In 2000, Rose-Hulman submitted a proposal to the National Science Foundation to develop educational materials that would improve the outcomes from the electrical systems course taken by ME students. A few of the general educational practices guiding the course design are described below.

1. Students should come to class prepared and familiar with the topics to be discussed in class.

2. Students should expect a significant amount of work outside of class.

3. Learning aids should be made available to students to help their work to be effective and efficient.

4. Electrical systems should be presented to ME students in the context of mechanical engineering. That is, discussions of measurement and instrumentation will be placed in the context of those tasks the working mechanical engineer will typically be called upon to accomplish. Discussions of instrumentation could be embedded in the context of engine design and emissions analysis. A discussion of industrial power distribution could be placed in the context of plant engineering.

Embedding the content of these courses in the context of the students' chosen discipline is consistent with constructivist theories of knowledge which state that the assimilation of new knowledge is aided by connecting to an existing base of knowledge. ${ }^{4,5}$ We need to bring these established educational ideas to the engineering service course. It is crucial that these students tie the knowledge gained in these service courses to that of their major discipline.

5. We should help our students develop the capacity for reflective thought. It is well known that reflection and self-assessment is an essential aspect of constructing knowledge and meaning. Long ago, John Dewey emphasized the importance of reflective thinking as an educational goal. ${ }^{6}$ He argued that students should be asked to reflect, to perform selfassessments of their understanding. Donald Schön also points to the need for reflection and argues that the educational preparation engineering professionals presently receive often does not allow them to develop critical thinking skills. ${ }^{7}$ 
6. Active learning and writing are valuable tools that can be used to introduce reflection and deep thought on the part of the students. The collaborative and active learning techniques described by Johnson, Johnson, and Smith and Slavin can be used to improve the understanding of many students who are not effectively engaged with other techniques. ${ }^{8,9}$

7. Writing can be used to introduce critical thinking and reflection. The habits developed when writing - thinking comprehensively, expecting to rework the initial results, and knowing there is no single correct answer-are indispensable in educating what Schön calls the reflective practitioner. These steps are included in most descriptions of the design process, and it is particularly important that writing be thoroughly integrated into engineering education since some of the most central elements of the design process are shared by writing. ${ }^{10}$ Both processes have a preliminary creative stage—often termed brainstorming in design and prewriting in writing. A recursive procedure, based on feedback from observations, is then used for gradual improvement until some acceptable solution is reached. Implicit in both processes is the crucial idea that there is often more than one acceptable solution and that often a unique "correct" solution does not exist.

\section{Curriculum Design}

Students must see this course as an integral part of their education and not as a course added as almost an afterthought, a course added only to provide "breadth" and one that contains nothing really necessary to the mechanical engineer. The use and understanding of electrical systems must be demonstrated to be part of what every mechanical engineer should know. If this fact is not made clear to students, if they believe that mechanical engineers do not need to know this "electrical stuff," then the students, the class, and instructors teaching the class will be prevented from achieving the success they otherwise might.

If this is what we believe, if we really do view electrical systems as a vital component of ME curricula, then we must pay more than just lip service. The course should build on the knowledge and skills the students have used in previous courses. One could do worse than constructing the first HW assignment in this course from material present in these courses. Students would then understand 1)that they are expected to recall material learned in previous classes and 2)the course has been designed with them in mind.

Ideally, the course should be designed to serve as a prerequisite course for required courses in mechanical engineering. Possibilities for these required courses include courses in measurement, controls, and the design of experiments.

At Rose-Hulman, the redesigned electrical systems course will most often be taken by ME students in the fall of their junior year. It will build on knowledge and skills developed in freshman physics classes and sophomore courses in engineering science that include system dynamics. Topics such as DC and AC circuit analysis, transient analysis, frequency response, and Fourier analysis have been seen by the students in prior classes. To be sure, some of the topics have been covered more thoroughly than others. Fourier analysis, for example, has not been developed or used as thoroughly as some other topics. This said, however, it is still better to introduce the topic as one in which the students have had prior exposure. 
Integrating the course into the ME curriculum, and keeping it an integral part of the ME curriculum, is only possible if the faculty members involved, both in ME and ECE, are able to keep communication channels open. The class, although taught by ECE faculty, cannot be viewed as being "owned" by the ECE department. The content and changes in the content affect ME students and ME courses. Conversely, changes in ME courses that provide background knowledge for the ECE course cannot be changed without affecting the ECE service course. As part of this effort to better integrate the electrical service course into the ME curriculum, the ME curriculum committee is considering making the electrical systems course a prerequisite to $\mathrm{ME}$ 311, Mechanical Measurements, a required, junior-level, ME core course. As the class evolves, we hope to include ME 406, Controls, as another ME core course that lists the electrical systems course as prerequisite.

Our primary object in this integration is student motivation. Mechanical engineering students will be better motivated to work hard and to value the course if they see that it really does build on their previous work and that it really does prepare them for future courses in the ME curriculum. Compare the attitude that students are likely to have towards such a course to the attitude of students entering an electrical systems service course presented with little regard or awareness of their previous work, a survey course where the coverage is broad with subjects being treated with little depth and almost no applications.

Many of you are likely aware of these types of courses. We are. The question repeatedly heard in these classes is "Why do we need to know this material?" The answer frequently heard in reply is: "In order to perform [substitute here some useful tool or technique], we must first become familiar with this knowledge." Then, more often than not, the promised useful tool or technique is not used at all or else not explored in any depth. The result is that material is presented, exams are taken, and grades are assigned. Those students who demonstrate minimal knowledge and can solve certain classes of problems pass the course but are still being unable to approach tasks in their discipline with a significant electrical component. Most students leave these courses without a high level of confidence or competence, and many students leave with an active aversion to any work that involves electrical systems.

This type of course - a survey course where many topics are given superficial coverage-results in bored and disengaged students who gain little useful knowledge. Instructors in these courses tell themselves that, with a sound knowledge of the basics, at least the mechanical engineer can learn about a particular area of electrical systems or instrumentation in more detail when the need arises. This is no doubt true for the best students, but, then again, our best students can likely learn the necessary material in any case. The challenge and opportunity lies in motivating good to below average students. We need to engage them in the study of electrical engineering by showing them the relevance that electrical systems have to their major course of study. We need to make this knowledge more accessible by making connections between it and their existing knowledge base.

We plan to leave this type of course behind, to consider the students' viewpoints, to take advantage of ME faculty advice, and to learn from our industrial partners. 


\section{Course Design}

Our starting point is simple. For any course to be successful, one must have motivated students, they must be required to work hard, and a learning environment must be made available to them so that they can learn both effectively and efficiently. Motivation is partially addressed in our plans, discussed above, for integrating the course into the ME curriculum. While this step is vital in obtaining initial buy-in on the part of the students, the material must be presented to ME students with due consideration of their background and perspective. Topics that hold intrinsic interest for the ECE student might be interesting to the ME student only in its utility in analysis or in the context of a larger system having the electrical system only as a part.

The hope is to include some of the best available educational practices in the course. These practices include on-line quizzes, a studio format, active and experiential learning, and a variety of student learning aids.

We intend to encourage students to study material before coming to class. Students will study, explore, and work with topics before they are introduced in class. That is, we are really going to ask that students come to class prepared. First exposure to many topics will be placed outside the classroom. On-line quizzing systems will be utilized to meet this objective. In preparation for the quizzes, students will study the textbook and will work through specially designed on-line tutorials. They will then take on-line quizzes. The quizzing system will be used in a gentle manner. That is, students will be given more than one opportunity to perform well on the quizzes. If they do not score well the first time, they will have a second and even a third opportunity to study the text, work through the tutorials, and take the quizzes. On-line quizzing systems used in this manner have at least four benefits: 1)students are made more responsible for their own learning, 2)students get immediate feedback on their learning, 3)extra time is made available in class for active learning, for discussion, for experiment, for in-depth learning, and 4)the data gathered can be used as a powerful assessment tool to study student learning. If students fail to take these on-line quizzes, they will not pass the course. We hope this carrotand-stick approach (the stick being its use and the carrot being our gentle use of it together with the availability of tutorial materials) will be effective in placing first-exposure to class materials outside of the classroom.

A studio format will be used where lecture and laboratory work takes place in the same workspace. The class meets for 2 hours 3 times each week. These longer class periods are effective in maintaining cohesion and allow students to become immersed in the study of electrical systems. The studio format permits an environment in which students learn technical content while gaining experience in important skills such as teaming and communication. What makes the studio approach particularly effective in entry-level courses such as the electrical systems course discussed here is that particular experimental difficulties in electrical systems such as inadvertent grounding through oscilloscope probes, wiring problems, inappropriate signal conditioning, or oscilloscope triggering problems can be handled in small steps and can be repeated and reinforced throughout the course. For students to really understand experimental technique, repeated use and periodic testing is essential. 
Computer tools will be used for computation and simulation. MATLAB, PSPICE, Simulink, and LabVIEW will be used in the course for computation, simulation, and experimental design. Students will use analysis, simulation, and experiment in their studio classroom work.

This class will be a rigorous one, and students will need to study hard outside of class. Setting all learning theory and methods aside, we feel that there is little substitute for student time-ontask. This is obtained through motivation, high standards, and designing an engaging student learning environment. A variety of tutoring tools and learning resources are being developed to assist students when they study outside of class. The materials being developed will help make this time well spent. These resources include on-line multileveled problem solutions in an intuitive point-and-click format, lecture notes, and a resource CD with short video clips giving presentations on important topics and background information for in-depth learning. The multileveled problem solutions will provide clear discussions and explorations of topics presented in class. They will also have depth. That is, students can navigate these documents to begin with, for example, basic DC circuit analysis, then to AC steady-state analysis, then to a closer look at the inductance, then to a discussion of Faraday's and Ampere's laws, and might end with an exploration of electromagnetic compatibility. In this way, students of all levels will be provided tools to aid in their learning. Even the very best students will find these solutions valuable and interesting. Students will also be provided with resource CDs containing short video clips (perhaps 2-10 minutes in length) that provide instruction on various topics - from presentations on various topics in electrical systems, to using simulation tools, to using laboratory equipment. We hope to address the needs of students with a variety of learning styles, and we expect that these on-line aids will be well received by a high percentage of students.

High standards will be used and rigorous testing in both theory and laboratory technique will be conducted. We will have high expectations of the students. These expectations will include simulation and laboratory skills, not only theoretical or analysis skills. Laboratory practicums will be administered to individual students to encourage all students to develop their laboratory skills. Homework, quizzes, and exams will include simulation exercises.

\section{Assessment}

Assessment and continuous improvement are integral to this project. A multileveled assessment strategy is being developed to gather data that will both allow a comparison with baseline data on the existing course as well as to inform course improvement processes. Tools include student surveys, focus groups, observations in subsequent courses, data from the on-line quizzing system, and RosE-Portfolio (Rose-Hulman's electronic portfolio system). Our aim is to gather meaningful data while not burdening the student with too many assessment activities.

An advisory board of nationally-recognized experts in engineering education and assessment will assist in reviewing the educational materials developed, provide information for their continuous improvement, and assure that the materials developed can serve as a model for the development of service courses in electrical systems. Board members include Karl Smith from the University of Wisconsin-Madison, Gloria Rogers from Rose-Hulman, and Ken Connor from Rensselaer 
Institute of Technology. We hope to add a mechanical engineer to our advisory board membership, ideally one with both academic and industrial experience.

\section{Summary}

We describe the redesign of the electrical systems course to be offered to mechanical engineering majors. Major elements include a studio design, on-line quizzes, a variety of educational materials to aid study, active learning, and integrated assessment and continuous improvement. Topics in electrical systems will be presented in the context of mechanical engineering. Demonstrations of the on-line quizzing system, multileveled problem solutions in a point-andclick format, and the $\mathrm{CD}$ tutorial videos will be included in the conference presentation.

\section{Acknowledgements}

This work is supported by the National Science Foundation under Grant No. DUE 0088904.

\section{REFERENCES}

1. S. Ashley, "Getting a Hold on Mechatronics," Mechanical Engineering, 119, 60 (1997).

2. Elizabeth A. Bretz, "By-Wire Cars Turn the Corner," IEEE Spectrum, April 2001, pp. 68-73.

3. Arthur W. Chickering and Zelda F. Gamson, "Applying the Seven Principles for Good Practice for Undergraduate Education, ," New Directions for Teaching and Learning, No. 47

4. Linda Lambert et al, The Constructivist Leader, Teachers College Press, 1995.

5. Noel Gough, "All around the world: Science education, constructivism, and globalization," J. Instructional Psychology, vol. 25, p7, 1998.

6. John Dewey, How We Think: A Restatement of the Relation of Reflective Thinking to the Educational Process, D.C. Heath and Company, 1933.

7. Donald A. Schön, Educating the Reflective Practitioner, Jossey-Bass Publishers, 1990.

8. David Johnson, Roger Johnson, and Karl Smith, Active Learning: Cooperation in the College Classroom, Interaction Book Company, 1998.

9. Robert E. Slavin, Cooperative Learning, Longman, 1983.

10. Edward Wheeler and Robert L. McDonald, "Writing in Engineering Courses," J. Engineering Education 89, 481 (2000).

\section{ZACHARIAH CHAMBERS}

Zachariah Chambers received his Ph.D. from the University of Tennessee, Knoxville in 2001 and is currently an Assistant Professor of Mechanical Engineering at Rose-Hulman Institute of Technology. His specialty is computational fluid dynamics. Previously, Dr. Chambers developed several Internet-based distance education courses at the University of Tennessee using streaming video, interactive chat, on-line homework, and exams.

\section{CLIFF GRIGG}

Cliff Grigg obtained his Ph.D. in electrical engineering from University of Manchester Institute of Science \& Technology (UK) in 1977. He is currently Professor of Electrical \& Computer Engineering at Rose-Hulman Institute of Technology. His teaching interests are electrical power systems, machines, and circuit analysis. He has eighteen years teaching and sixteen years industrial experience.

RICHARD A. LAYTON

Richard A. Layton received his Ph.D. from the University of Washington in 1995, taught for four years at North 
Carolina A\&T State University, and is currently an Assistant Professor of Mechanical Engineering at Rose-Hulman Institute of Technology with a specialty in system dynamics. Previously, Dr. Layton worked for 12 years in industry, culminating as a technical group head and project manager. He is a registered Professional Engineer.

\section{EDWARD WHEELER}

Edward Wheeler received his Ph.D. from the University of Missouri-Rolla in 1996 and is an Assistant Professor in Electrical and Computer Engineering at Rose-Hulman Institute of Technology. His interests include the electrical and optical properties of materials, engineering education, and electromagnetics. He has eight years of industrial experience and is active in ASEE, IEEE, and APS. 